\title{
ASSURED-SQVM Diagnostics for COVID-19: Addressing the Why, When, Where, Who, What and How of Testing.
}

\author{
Mukesh Kumar,", and Suri S. lyer ${ }^{2, *}$ \\ ${ }^{1} 622$ Petit Science Center, Department of Biology, \\ 2788 Petit Science Center, Department of Chemistry, \\ Center for Diagnostics and Therapeutics, 161 Jesse Hill Jr. Drive, Georgia State University, \\ Atlanta, Georgia 30302-4098. Email: mkumar8@gsu.edu and siyer@gsu.edu
}

\begin{abstract}
COVID-19, the disease caused by the new coronavirus, SARS-CoV-2, has caused significant human and economic burden. Of the three major methods to mitigate the effect of the virus, diagnostics have become the focal point because vaccines and therapeutics, despite the intense effort of scientists worldwide, will take months to develop, test for safety and efficacy, scaleup and distribute to millions. This perspective aims to clarify some of the issues related to COVID-19 diagnostics and highlights some of the challenges key stakeholders including policymakers, businesses, managers, scientists and individuals face during this evolving pandemic.
\end{abstract}

Keywords: COVID-19; SARS-CoV-2; diagnostics; point of care

\section{INTRODUCTION}

COVID-19, the disease caused by the new coronavirus, SARS-CoV-2, has caused significant human and economic burden. As of May 6, 2020, the number of confirmed cases worldwide is over 3.7 million and 250,000 deaths [1, 2]. Approximately 7.2 billion human beings live on this planet, indicating that a very small percentage, $0.04 \%$ are infected with the virus. Albeit this low percentage, the high transmissibility, complex patchwork of quarantine measures in different communities, unanswered questions related to long term immunity and potential antibody enhancement mechanisms of infection indicate that it is very likely that SARS-CoV-2 will continue to create havoc on our lives for several years. The ferocity of this virus cannot be overstated as it has been demonstrated to infect multiple organs with significant damage to the lungs early in the infection process $[3,4]$. Of the three major methods to mitigate the effect of the virus, diagnostics have become the focal point because vaccines and therapeutics, despite the intense effort of scientists worldwide, will take months to develop, test for safety and efficacy, scaleup and distribute to millions [5, 6]. Testing has taken center stage as a growing chorus of economists and policy makers have emphasized that shutdowns are not a long-term solution as $\sim 33$ million or $\sim 23 \%$ of the working population filed for unemployment in the United States within five weeks of the outbreak [7, 8]. "Immunity passports" based on current diagnostics are being suggested as one of the potential ways to reopen the economy [6, 9]. However, diagnostics for COVID-19 cannot be classified as a simple yes/no answer due to the complex nature of this disease. In addition, the general population (including some healthcare professionals) are not fully aware of the intricacies of testing, differences between analytical and clinical specificity and sensitivity, limitations and differences in tests, and how tests assist in the clinical decision making process by a professional. 
This perspective aims to clarify some of the issues related to COVID-19 diagnostics and highlights some of the challenges key stakeholders including policymakers, businesses, managers, scientists and individuals face during this evolving pandemic.

\section{RESULTS AND DISCUSSION}

Why test?: While this is a fundamental question for most people, a significant percentage of the populace are prone to asking these questions (i) Why test when vaccines or therapies to treat the disease are unavailable? (ii) The tests are not $100 \%$ accurate, so why take the risk and be quarantined for 14 days when I have very limited or no financial resources? (iii) The cost of an excellent test is prohibitively expensive, especially if testing is required throughout the quarantine period, how can I afford it? and (iv) Why can't we just wait for herd immunity?

Health is wealth: The primary reason for testing in an outbreak is to alleviate the health and economic burden for the individual and the entire community $[10,11]$. The society as a whole, and economic activity will invariably suffer if a significant population is sick and the healthcare system is overburdened. Good health precedes economic activity and growth. Economically, it is cost effective to quarantine a positive SARS-CoV-2 patient and conduct an aggressive contact tracing program [12, 13]. Unfortunately, the silent and rapid transmission of this strain limited this first and best option. The next obvious step was to initiate shutdowns and entire countries were asked to shelter in place. Initially, these shutdowns were mandated to decrease the healthcare burden because most communities did not have sufficient protective equipment, ventilators and resources to fight against the virus [14]. Emerging countries still do not have sufficient hospital beds for their communities. In wealthier nations, governments have increased their stockpiles of essential medical supplies and equipment leading the question of why test now when there are sufficient ICUs, beds and other equipment for a projected spike in number of cases? Unfortunately, even in advanced countries with significant resources, skilled personnel need to work around the clock to monitor patients with ARDS (Acute Respiratory Distress Syndrome). There is a shortage of healthcare professionals with specialized training [15]. The argument of a low death rate of $1-2 \%$ fades when it is estimated that $\sim 10-20 \%$ of positive SARS-CoV-2 patients will suffer from ARDS and require hospitalization and $2-5 \%$ requires major intervention and ICU care [4, 16]. The intervention requires experts from different specialties; for example, if a patient is admitted to a medical center with respiratory distress and a stroke caused by complications related to COVID-19, the individual will require a team of professionals. The team includes an emergency care physician, respiratory therapist, pulmonologist, primary care physician, a neurologist, a cardiologist, a rehabilitation physician, case manager, social worker, nurses and technicians. The economic burden for the patient can mount upto thousands of dollars, depending on the case severity. From a societal perspective, insurance companies and hospitals may have to close $[17,18]$. As an example, if a community of 100,000 inhabitants are exposed to the virus, 10,000-20,000 will require hospitalization and 1000-2000 will require ICU admission. It is almost impossible for any healthcare system to manage such a high volume of patients for days or weeks even if hospitalizations occur over months [19]. In addition to patients, the high concentration of the virus in patients increases exposure to healthcare professionals. When a patient is suffering from ARDS and requires intubation, close patient contact is unavoidable [17, 20]. The virus concentration in the ICU where the intubation or other invasive procedures are being performed is 
extremely high, leading to a high rate of healthcare professional infections. The economic and health burden increases exponentially when healthcare professionals are infected. Healthcare professionals may have to be hospitalized or quarantined and the hospital will have fewer staff members to care for patients [21]. For these reasons and the difficulty of eliminating it in locations with a significant proportion of individuals with underlying health conditions, it is imperative that testing, along with other countermeasures are followed.

When to test: SARS-CoV-2 enters the host through the ACE-2 receptors on epithelial cells present in the respiratory tract, resulting in non-specific symptoms such as a mild cold, headache and general malaise $[22,23]$. In most people, particularly in children and young adults under the age of nineteen, these mild symptoms fade with time. A significant number of adults are asymptomatic. However, 20\% of infected individuals develop moderate to severe symptoms which include a fever that doesn't subside easily, headache, diarrhea and loss of smell and taste in some individuals [23]. Interestingly, the severity increases suddenly in some individuals after 5-10 days. This presents a unique testing challenge for several reasons. (1) If an individual is asymptomatic or has mild symptoms resembling that of a common cold, he/she may not seek medical care until the infection has progressed. During this time, the individual will unwittingly spread the virus to others. (2) A significant percentage of the population is unaware of an underlying conditions such as hypertension or diabetes. These patients are more likely to require medical attention or become hospitalized, but only after the virus has established a foothold in their bodies [24, 25]. (3) At the present time, the median time to clear the virus is not established and is most likely dependent on the health of the individual, with the caveat that healthy individuals are not refractory to contracting severe disease [26]. Given these features of the virus, testing must be performed early, regularly and randomly in communities with limited number of known cases and even in communities where the number of new cases has apparently decreased significantly. In communities with a large number of cases, a combination of shelter in place coupled with aggressive large scale and random testing for the presence of the virus and for antibodies produced against the virus must be performed.

The three major classes of diagnostics, i.e. tests for virus, antibody and inflammatory biomarkers, are available for different times and provide uniquely distinct information [27, 28] (Figure 1). For example, the timeline for antibody testing doesn't follow the timeline for virus testing as it takes 5-10 days after onset of infection for the body to produce sufficient antibody concentration [29]. Additionally, test sensitivity must also be taken into consideration; if the limit of detection of the test is higher than the viral concentration at the time of sample collection, a false negative result will be recorded. In contrast, if a test has demonstrated to have an extremely low limit of detection, there is an extremely high likelihood that cross-reactivity increases, leading to false positive results. Therefore, appropriate tests must be used at different times with tests that have excellent limit of detection with minimal or no cross-reactivity.

Where to test: While an ideal approach may be feasible for smaller communities, it is unrealistic to produce and distribute millions of tests for larger communities and countries. A stratification strategy is most pertinent. Testing must be conducted in localities that have been demonstrated to have a high incidence of virus spread and places that cannot strictly adhere to social distancing. These locations include hospitals, emergency rooms, nursing homes and assisted living facilities, retirement communities, food processing industries, grocery chains, prisons, cruise ships, refugee camps, schools and universities. The common denominator of all these places is high human traffic and interactions in close quarters. 
Nursing homes and assisted living facilities present unique challenges because close contact between caregivers and residents cannot be avoided [21,30]. Once the virus establishes a foothold in a nursing home, it spreads rapidly, has a very high death rate and is proving to be very difficult to eliminate. Unfortunately, caregivers and residents are falling sick at very high rates. These places require more stringent testing.

Who to test: It is unrealistic to test millions of people daily. A stratification approach must be undertaken with testing prioritized for high-risk individuals and individuals who are constantly being exposed to the virus [31]. The hospital setting ranks among the top. In a hospital setting, all essential personnel who are working in the hospital must be tested for three reasons: (i) Protecting the health and well-being of the healthcare professional is of the highest importance because they are on the frontlines of this war. Virus concentration is very high in a hospital setting as a significant percentage of patients are spreading the virus. While healthcare professionals are taking all precautions and using protective equipment, accidental exposure can occur in emergency situations where a high volume of patients need assistance [21]. (ii) If a healthcare professional is tested positive, he/she will have to be quarantined, which means one less person to support an already strained healthcare system. (iii) Since a large proportion have no or mild symptoms, healthcare professionals might be passing infections to other patients and their families. The first category includes individuals in very important positions who keep society stable and functioning; these include high-ranking government officials who set and execute policies, researchers and manufacturers developing vaccines, therapeutics, protective equipment and supplies, and people who provide security and maintain food supply chains. However, not everyone in these positions require testing, and daily testing may not be essential as these individuals do not come in regular contact like the hospital professionals. The second priority is healthcare professionals working in a high-risk community setting such as nursing homes, assisted living facility, retirement homes, etc. because the virus spreads rapidly in these communities. Caregivers are generally in very close contact with the individual performing tasks (such as providing medication, cleaning, showering, etc.) that require very close human contact and therefore transmission is at its peak [30]. The third priority is professionals at retail settings, specifically all individuals working in areas where customer interactions are high should be tested daily [31]. The reason is to limit spread: if a server in a restaurant is sick, the number of people he/she will infect is very high. Industries where personnel interactions cannot be avoided, but can only be minimized, fall into the same category. The fourth priority for testing should be citizens with co-morbidities since it has been proven that the virus exacts a significant toll on those with underlying health conditions [24, 25]. Within this group, age is also a factor that must be considered, because hospitalizations and death rates increase with age. If a new infection is detected, the individual must be quarantined and tested daily to determine if virus concentration is increasing or decreasing. The family and friends of the individual also must be tested and, if tested positive for SARS-CoV-2, they must be quarantined and tested regularly to limit spread. We note that the stratification strategy listed here are designed from the perspective of limiting spread, protecting vulnerable individuals and key personnel essential to the normal functioning of society.

What to test: Samples to test can be broken down into human and environmental samples. Testing in the environment is particularly useful in areas where space and resources are limited such as refugee camps, prisons, assisted living facilities and high density population centers to ensure that specific areas are decontaminated [32, 33]. For testing in humans, non-invasive samples are, by far, the best sample 
source as these samples do not require invasive techniques, assuming the tests are of equal precision. SARS-CoV-2 infects the upper and lower respiratory system and therefore, nasopharyngeal and throat swabs are optimal for direct detection of the virus [34]. Sputum is also a good sample source, although it may be difficult to collect samples from very sick patients. Coughing is very difficult for patients with respiratory distress; a similar issue has been well documented for TB patients [35]. However, sputum samples can be collected from individuals with mild or no symptoms. Other non-invasive samples are stool samples. Unfortunately, the virus is not seen in urine samples. Invasive samples include bronchoalveolar lavage fluid specimens, fibrobronchoscope brush biopsy and blood (with the caveat that the concentration of the virus in blood is low) [36]. Direct testing for virus presence in these invasive samples is not preferred. CT lung scans as non-invasive testing have shown significant promise as the lungs of infected patients show significant opaque lesions, but have mainly been used in limited hospital settings, due to low throughput and upfront instrument costs [37].

To determine if an individual has been exposed to the virus regardless of their symptoms and/or for surveillance purposes, antibody testing holds the key. Capillary blood is the current sample source, although the ideal test would be for the presence of $\lg A$ in saliva or sputum samples as it is non-invasive [36, 38, 39]. However, the concentration of IgA in saliva or sputum may be lower than blood samples. Testing for antibodies can be classified broadly into two types; binding and neutralizing antibodies. The latter becomes more relevant if it is used to determine if the individual has immunity upon reinfection by the same or similar strains $[9,38,40]$.

To test if a SARS-CoV-2 positive individual requires intensive intervention, testing for serum inflammatory biomarkers is the ideal candidate as the cytokines, chemokines and enzymes are mainly released in the blood [41]. Urine and saliva are being considered as alternate sample sources to test for inflammatory biomarkers, but research on those sample sources is still evolving [42]. A personalized testing approach using multiple biomarkers and quantification is important since some of the biomarkers may already be at an elevated in patients with chronic conditions, several of which are related to dysregulated immune systems.

How to test: To test for the presence of a virus, nasal and/or throat swabs are collected and sent to a central laboratory for processing. The samples are subjected to rRT-PCR analysis. Briefly, viral RNA present in the sample is amplified exponentially using a specific set of primers and detection using fluorescence dyes is performed [43]. There are several variations and improvements to the basic amplification process using LAMP, SAMBA, etc., to reduce time, number of steps and user-friendliness, but the basic principle relies on amplification followed by detection [44, 45]. Automation and integration have resulted in systems that have improved user-friendliness and trained personnel are not required. These systems have been developed for a variety of diseases and are being adapted for SARS-CoV-2 [46]. Other methods include growing the virus in a clinical/microbiology laboratory and/or testing for presence of viral antigens (Figure 2).

To test for the presence of antibodies generated by the body against SARS-CoV-2, whole blood or serum is collected. An ELISA (Enzyme Linked Immunosorbent Assay) is used to determine the presence of antibodies. Briefly, viral antigens are attached to the surface of microwells of a microtiter plate. The sample is added and after a set time, washed to remove non-specific binding proteins. Enzyme linked 
Anti-lgG or anti-IgM antibodies or a combination of enzyme linked antibodies are added, followed by a washing step and a final addition of the substrate, which will be converted to a colorimetric or fluorescent product [39]. If anti-SARS-CoV-2 antibodies are present, the color change can be measured and correlated to the concentration of the antibodies. Antibodies raised against anti-SARS-CoV-2 antibodies can also be used as a capturing molecule. Once ELISAs are developed and validated, the next obvious step is to convert the assay to a disposable lateral flow device similar to a home pregnancy kit, which can be mass produced at a very low cost and distributed worldwide. ELISAs can also be developed to determine if the antibodies are binding or neutralizing antibodies, but the process if more complicated because the body makes antibodies against a number of pathogens. High affinity molecules specific to the neutralizing antibodies need to be developed and validated. Alternatively, a concentration based method to differentiate between high and low affinity antibodies can be developed, but these methods are primarily restricted to a laboratory setting and commercial point-of-care (POC) diagnostics to detect neutralizing antibodies are still under development.

The quantification of inflammatory biomarkers is typically performed using venous blood. A panel of inflammatory biomarkers like TNF- $\alpha$, IL-6, elevated liver enzymes, etc. can be quantified using a blood test; using multiple biomarkers provides an overall picture of the "cytokine storm" that is not readily visualized by symptoms alone. There are some devices that measure one or more of the biomarkers, but there aren't a plethora of inexpensive POC diagnostics to detect a possible cytokine storm [47, 48]. Clinicians use standard blood tests to monitor these inflammatory biomarkers.

\section{Strengths and limitations of diagnostics:}

A. Direct detection of the virus: (1) Viral culture: Pros: Viral culture ranks as the best diagnostic test because it provides information about the viral concentration and viability [49-51]. No other test can inform if the virus is infectious or non-infectious. Subsequent analysis of the genomic analysis of the virus can provide detailed information about the origin, mutations, level of transmission and other intricate details of the virus. Cons: Viral culture requires additional biosafety level precautions, specialized equipment and trained personnel. The time-to-result are generally in days, although efforts are being made to decrease the times.

(2) RT-PCR tests: Pros: The specificity and sensitivity of these tests are unparalleled. The tests can be quantitative, but quantification requires specialized clinical laboratories with longer time-to-results [51, 52]. POC qualitative tests that use integrated sample handling, amplification and detection, providing a quick yes/no answer within minutes or hours are being used at some clinics [46, 53]. The user-friendliness of the devices and time-to-result are valuable features, especially in high volume settings. Since specific gene sequences are targeted, multiple pathogens can be detected using one instrument and multiple disposable cassettes. Alternatively, using a cassette that can test for multiple pathogens could also be used. Cons: The primary weakness is related to the upfront cost of the instrument, which is generally in thousands of dollars depending on the features of the instrument. When the cost of maintenance, disposable cassettes, and multiplexing capabilities are added, this diagnostic is unaffordable, although it could be argued that the economic cost of not testing is higher [54, 55]. If an individual needs to be tested daily over a standard fourteen day quarantine period, testing becomes impractical with these tests. Second, POC tests are not quantitative and therefore, it is not possible to ascertain if the viral 
concentration is increasing or decreasing. Third and most importantly, nucleic acid tests cannot differentiate between live and dead virus as the technology amplifies specific gene sequences, regardless of viability. A quantitative test performed daily is required to ascertain if the viral load is increasing over time to determine if the patient has viral remnants or is truly virus free [55].

(3) Detection of viral antigens using lateral flow disposable tests: Pros: These user-friendly, inexpensive tests can be mass produced rapidly and can be used to provide an on-site yes/no answer within minutes $[44,45]$. These tests can also be made to withstand high temperatures and humidity and therefore, can be deployed rapidly. Cons: The two major concerns are related to sensitivity and selectivity [56]. If antibodies raised against the new coronavirus are used, it is imperative that the antibodies are tested for cross-reactivity against similar strains and validated, or else the selectivity decreases. The tests detect viral antigens and therefore, cannot distinguish between viable and dead pathogens and quantification is generally not feasible with this technology.

B. Determination of prior infections: When an individual is exposed to the pathogen, the body will generate antibodies against the pathogen. These antibodies can be detected using lateral flow devices, where monoclonal antibodies against these antibodies can be generated [57]. Alternately, viral antigens can be used to capture these antibodies in a lateral flow format [44]. In the previous section, antibodies were used to capture viral antigens; here the format is reversed. The pros and cons of these tests are similar to the lateral flow tests described previously for direct detection of the pathogen.

Interpretations of results: Assuming that (i) the sample was collected, handled and transported according to $\mathrm{WHO}$ and CDC guidelines, (ii) the test has a high clinical selectivity and sensitivity, (iii) technicians performing the test were well trained, there are two possibilities for viral tests.

A. Positive results: If an individual is tested positive for SARS-CoV-2, the next step would be consult with the physician and follow the physician's recommendations; these may include hospitalization or quarantine at home. Unfortunately, at home tests are unavailable at the present time, and therefore, symptoms have to be monitored. From a public perspective, it is important that the individual stay under quarantine until symptoms have subsided and the individual is not shedding virus. It is quite possible that the result is false positive, for example, if the result is positive 3-4 weeks after the onset of infection, it is most likely that the test is detecting dead virus or fragments of the virus.

B. Negative results: At face value, a negative viral result means the person doesn't have the virus. However, the reality is more complicated because of the unique nature of the infection process. Testing early or late in the infection process can result in false negatives (Figure 3). A negative result does not necessarily mean that the individual is SARS-CoV-2 negative; it means that the individual didn't have the virus at the time of testing [58]. It could also mean that the individual had the virus previously, but the symptoms were mild or not noticeable and the immune system has cleared the pathogen. If a patient is presenting moderate symptoms and the result is negative, it could mean that the immune system has managed to decrease the virus concentration at the time when the sample was collected. Testing more frequently would confirm the diagnosis. A similar logic follows for tests that detect antibodies produced by the body in response to the infection. It is important to note that even if the individual has tested positive for antibodies against the virus, the concentration and neutralizing capability is not known, unless 
more involved testing in a clinical laboratory setting is performed. Most importantly, it is not clear at the present time if presence of antibodies prevents re-infection and/or provides long term immunity [9]. It is also unclear if the individual who has antibodies can act as a carrier and if these antibodies protect people from mutated strains. Taken together, the concept of "immunity passports", while exciting for opening large segments of the economy, is still in its infancy and shouldn't be used for major decisions in isolation without considering other factors. Unlike viral or antibody tests, there are no positive or negative results when testing for inflammation. Testing relies on a panel of inflammatory biomarkers [59]. These tests must be quantitative because individuals have baseline levels of these biomarkers, which increase upon injury. Baseline levels are highly dependent on underlying conditions of the patient. In addition, some individuals may be taking immunosuppressive drugs and therefore, the concentration of the biomarkers may be lower [60]. A personalized testing approach is required for inflammatory biomarker testing.

It is very important to note that results from any diagnostic for COVID-19 should be interpreted by a trained professional. For example, even after major technological advances and decades since the first home pregnancy test was introduced in 1976, home pregnancy tests are still not $100 \%$ accurate [61]. When diagnostics are being produced within days during an emergency pandemic, it is very likely that tests do not have the selectivity and sensitivity claimed by manufacturers, especially when these tests are being performed in the field. Clinicians consider other symptoms, factors such as underlying conditions, age, community outbreak data, etc. to confirm the diagnosis. These decisions are easier for the $10-20 \%$ of individuals who present typical COVID-19 symptoms and are positive for virus, but the confirmation becomes more difficult when people with mild or no symptoms test negative.

The "ideal" diagnostic: Diagnostic requirements for different stakeholders vary significantly depending on their roles in a community. A diagnostic for COVID-19 for clinicians and healthcare professionals require different features than a diagnostic required for a produce manager in a grocery store because they want the diagnostic to tell them different things. For example, a physician may want to know if a set of inflammatory biomarkers are increasing as a function of time in a patient; whereas the produce manager will want to know only if his/her employees have SARS-CoV-2 and if they are spreading it to customers and other employees. The former will allow the clinician to determine if the patient requires more intervention; the latter will use the results to determine if the store can be open for business. Epidemiologists use diagnostics for surveillance purposes and build models for policymakers to make informed decisions that affect the entire community and not necessarily for a specific individual; in contrast, an individual needs diagnostics depending on his/her situation. Individuals with underlying health conditions or individuals with family, friends and colleagues with hypertension, diabetes and other morbidities that make then susceptible to severe disease manifestations will find at home diagnostics indispensable.

Some of the questions and decision making process that could help personnel in different professions make appropriate decisions are given below (Figure 4). The questions are not exhaustive, but provides a sense of the different needs of different stakeholders. More detailed guidelines have been released by the multiple government agencies [62].

1. Clinicians, healthcare professionals: The primary aim of a clinician is treating the patient. The diagnostic is expected to assist the clinicians in their decision making process about treatment. Some of 
the most pressing questions are: (i) Does my patient have SARS-CoV-2 or is it a different pathogen? The treatment options differ depending on the answer. (ii) If my patient is SARS-CoV-2 positive, can the diagnostic quantify the viral load? If it is a very high concentration, patients need to be quarantined and secondly, the patient needs to be monitored for adverse reactions. (iii) Can the diagnostic tell me if the patient's inflammatory biomarkers are increasing as a function of time? Since every individual is unique, a personalized diagnostic approach is required, where close monitoring of the inflammatory biomarkers as a function of time will ascertain if the patient needs more (or less) intervention, is required. Remote monitoring would be ideal because the clinician or healthcare professional would not have to come in close contact with the patient. (iv) If the patient is quarantined in the hospital or at home, can the diagnostic determine the viral load daily to help me determine when to release him/her from quarantine?

2. Policymakers and government officials: The primary aim of these stakeholders is to use diagnostics as one of the tools to make informed decisions about society and their communities. Diagnostics that determine number of prior and current rate of infection and hotspots is of utmost importance for them for implementing appropriate countermeasures. Epidemiologists use information obtained from these diagnostics to develop models that will assist them in predicting future outbreaks. These diagnostics can be primarily qualitative; quantification and diagnostics for inflammatory biomarkers will generally not affect their decision-making process. The questions that policymakers require from diagnostics are: (i) Will the diagnostics tell us what percentage of the population are positive? (ii) Can the diagnostics identify hotspots and identify local and imported infections? (iii) Can the diagnostics be used to model the infection spread? Often, they have to balance multiple priorities from experts from different sectors to look at cost/benefit analysis. For example, it may seem prudent from an epidemiological standpoint to have a complete shutdown of a community for months; it is unreasonable from an economic perspective as loss of economic activity will lead to significant mortality and morbidity.

3. Officials at high density living conditions (eg. nursing homes, assisted living facilities, cruise lines, prisons, refugee camps): The aim of the managers in these facilities are multifold, including, but not limited to the health of their residents and their personnel. These facilities are generally no/low resource as they have limited medical equipment and supplies. Therefore, diagnostics must be designed accordingly. Some questions related to the testing aspects are: (i) Can the diagnostic determine if healthcare professionals, technicians, caregivers and visitors are virus free? (ii) If one of residents is tested positive, can a diagnostic ascertain if the resident needs to be hospitalized or released from quarantine? (iii) Can the diagnostic detect virus in the environment for decontamination?

4. Overseers of areas with high traffic or human interactions (e.g. schools, universities, entertainment complexes, theme parks, beaches, sports venues): The primary aim of the administrators of these organizations is related to containment and isolation, while performing the essential functions of the institutions. For example, school principals and university presidents do not want a SARS-CoV-2 student or employee on their premises for fear of spreading the virus. The number of students in large open campuses is an additional challenge. The requirements from a diagnostic are: (i) Can the diagnostic be administrated to students entering campus with minimal interference and privacy? (ii) Can the result be obtained in minutes? (iii) Can the diagnostic detect virus in the classroom and common areas for decontamination? 
5. Individuals: The primary aim of the vast majority of citizens want to protect themselves and their loved ones. The requirements for diagnostics are (i) Is it precise and accurate? (ii) Is it complicated? (iii) Is it inexpensive? (iv) Are results rapid? (v) Can it be stored in medicine cabinets for a long time and portable?

Challenges for the diagnostic community: (i) ASSURED-SQVM principles: The ideal diagnostic should follow the ASSURED (Affordable, Selective, Sensitive, User-friendly, Rapid and Robust, Equipment-free Deliverable to end-users) principles of point of care diagnostics developed by the WHO for infectious diseases [63] (Table 1). These ASSURED principles become increasingly important in the current coronavirus pandemic particularly because of the significant health and economic impact and disparity at a global level. For example, some countries have an efficient healthcare system that can afford expensive diagnostics unlike others, where healthcare systems are limited in scope and severely strained even before this outbreak. Communities with advanced testing, healthcare systems, lower economic disparities and a cohesive evidence based strategy are able to cope with the economic fallout than resource-poor communities. In addition to these ASSURED requirements, the nature and timeline of the infection requires additional features, that have been coined here as SQVM (Self-testing, Quantification, Viability and Multiplexing). Briefly, Self-testing is highly desirable to limit personal interactions and maintain social distancing in the privacy of homes [64]. Self-testing can be combined with telemedicine for patients to communicate the results to their physicians [65]. Quantification is important for individuals to determine if there is an increase or decrease in the viral load, antibody or inflammatory biomarkers during the 14 day quarantine period $[66,67]$. Tests that can determine Viability of SARS-CoV-2 in an environmental or human sample could provide additional information to first responders and healthcare professionals to perform adequate countermeasures [32]. Finally, Multiplexing will be of highest priority during the influenza season, because symptoms of the new coronavirus and influenza overlap [68,69]. Rapid detection of the presence and quantification of bacterial respiratory pathogens such as Streptococcus pneumoniae take on increasing urgency during the influenza season, because bacterial pneumonia is often the more severe outcome of the initial influenza infection [70]. There are numerous exciting emerging technologies that address one or more of these

ASSURED-SQVM principles; however, none of the existing technologies can satisfy all of these principles. The technological demands are challenging, however, human ingenuity can be applied to develop excellent diagnostics. For example, if a diagnostic lacks user-friendliness, trained personnel can consult with individuals at homes to self-test using video conferencing. Additionally, as described in the previous section, different stakeholders require different information. At the very minimum, inexpensive, user-friendly, selective and sensitive self-testing diagnostics that can detect and quantify SARS-CoV-2 would be extremely valuable for mitigating efforts. It is also imperative that analytical chemists and assay developers collaborate with stakeholders early in the development process. For example, it doesn't make sense to develop a test that can detect 10 viral particles for a clinical setting, if patients are presenting 1,000 particles at an urgent clinic or emergency room. Similarly, it doesn't make sense to develop a multistep process for reagents, when industries prefer less complicated steps for scale up and distribution. Regular communication and developing realistic plans with go/no-go decisions and alternate strategies with stakeholders and the team is critical in a pandemic situation. 
(ii) Influenza and SARS-CoV-2: The months leading to the 2020-2021 influenza season will be remembered as a "call to arms" for the diagnostic community as the primary line of attack of the two pathogens, influenza and SARS-CoV-2, is the upper respiratory system and the lungs. The CDC estimates that influenza infections ranged between 39 to 56 million infections in 2019-2020 [71]. In contrast to SARS-COV-2 which has mostly spared children and young adults, influenza infects seniors, children and individuals with weak or compromised immune systems [72]. It is not clear how individuals and society will fare if both pathogens attack at the same time. Although influenza vaccines provide substantial health benefits and decrease number of hospitalizations and death, vaccine effectiveness is only 50\% for most seasons [71]. The possibility of a new influenza strain capable of causing a pandemic, similar to the 2009 "swine flu strain" cannot be discounted. The symptoms of the two pathogens are overlapping, which makes it extremely difficult to diagnose. Unfortunately, ASSURED-SQVM diagnostics that can detect influenza, SARS-CoV-2, co-infections and/or bacterial infections are unavailable at the present time. This is a major challenge for diagnostic developers and the larger scientific community [69].

(iii) Communication challenges: In addition to the technological challenges, one of the often overlooked, major challenges for the scientific community is to communicate the nuances of testing, outcomes and the decision making process to the broader non-scientific community. Diagnosis is especially difficult because some individuals are asymptomatic. This is in contrast to other diseases where symptoms are the usually the first indicator before using tests. If a child were not sick, parents would not take the child to the physician. In addition, there is a plethora of information on the internet and in various social media formats that is overwhelming. An internet search for "Diagnostics for coronavirus" yields over $137,000,000$ results in less than one second. A more focused search for articles with the same terms results in over 24,000 scientific articles and patents; a similar search on the preprint server medrxiv results in over 800 non-peer reviewed publications. Unfortunately, with a deep desire of the masses for a rapid return to normalcy, coupled with the aspiration of scientists to be the first to provide solutions, several methods claiming to be the best before validation are published. The research findings are publicized in multiple news outlets and amplified by social media. Every news cycle has reports of new innovations that claim the development of "high selectivity and sensitivity" without testing clinical samples. Claims of "rapid" and "within 15 minutes" without taking sample preparation time into consideration are becoming commonplace. Non-scientific individuals are unfamiliar with limit of detection, differences between analytical and clinical selectivity and sensitivity, positive and negative predictive values, time to test, etc. (Table 2) and hence add to the complexity of the chaos. For example, an individual may test negative on day 1 of the onset of infection if the concentration of the virus on the nasal swab is lower than the limit of detection and positive on day 3, when the viral load is higher than the limit of detection. It is also quite possible that the diagnostic had a low accuracy leading to conflicting results on both days. Temperature sensors are being used at airports and transportation hubs, but may not be particularly useful since individuals generally develop fever after a week of onset of infection. Beyond these issues, the nuances of clinical diagnostics need to be communicated better to the general public. For example, a test has been demonstrated to have $95 \%$ clinical sensitivity and selectivity in a well-controlled clinical study, can lead to 90,000 false positive cases and 10,000 false negative cases if the prevalence of the disease is $~ 10 \%$ and two million samples have been tested (Figure 4). The 10,000 false negative individuals would potentially spread it. Use of multiple biomarkers, frequent testing and quantitative results could solve this problem. Additionally, with hundreds of millions of dollars at stake to develop rapid diagnostics quickly, exaggeration of the research and results becomes commonplace. It is imperative for 
the diagnostic community to address these issues, or else it will lead to a lack of credibility for testing, which defeats the purpose of testing.

\section{Conclusions:}

This is a war against an almost "perfect" enemy. Like most successful opponents, the virus has focused on our blind spots and turned our strengths into weaknesses. (i) It infiltrates silently. Humans, by nature and by logic, do not test unless we exhibit symptoms. The virus exploited this seemingly sound logic. Individuals spread virus in the early stages when they are asymptomatic or have mild symptoms. Its early incursions were missed because it transmitted rapidly and silently across the globe within weeks, entering 188 countries and overwhelming healthcare systems. (ii) It stays longer: The median time from onset to clearance is approximately 14 days [23]. This strategy is highly effective to destroy economic activity, which, in the long term, is expected to significantly increase morbidity and mortality. With limited mobility and behavioral changes, economic activity has cratered allowing the virus to cause more suffering and death due to increased poverty and other social ills. (iii) It kills selectively. It doesn't kill all vulnerable sections of society, but is highly selective. It kills select individuals with underlying health conditions (particularly in nursing homes and assisted living facilities) but seems to leave the majority of infants and children with mild or minimal symptoms, although rare cases of inflammation in children are being reported [73, 74]. At the present time, we don't understand its selection process. (iv) It uses our best defenses against ourselves: It achieves this objective in two ways; inside and outside the bodies in a seemingly (because we don't understand it) random manner. (a) Internal: The immune system is our best defense against all pathogens. However, the response must be tempered. If overactivated, it will lead to a "cytokine storm" and subsequent organ failure [41]. Select healthy individuals without comorbidities, produce a violent immune reaction and have to be hospitalized, whereas the vast majority produce no such reaction. Interestingly, the immune overreaction happens suddenly without warning after 5-10 days from onset of infection [23,67]. This speaks to the craftiness of the virus; some patients have been sent home for quarantine because they have mild symptoms. Some patients have come back when the symptoms increase, unfortunately in other patients, strokes and other complications have been fatal. (b) External: Two of our strengths as a diverse society is to think freely and develop creative solutions towards solving seemingly intractable problems. This strength has allowed us to eradicate several pathogens, but only when a singular public policy is followed. Unfortunately, multiple options, none of which are perfect, has led to different public policies and a patchwork of containment strategies. This is clearly seen in the United States, where different states have pursued different policies and it is widely expected that a resurgence of infections will occur. It has also forced us to forego socialization, one of the fundamental aspects of being human, as a defense mechanism, which has led to significant economic damage.

Diagnostics are excellent weapons and can be tailored to blunt the sinister attacks of the virus. Diagnostics can (i) Limit the silent spread, (ii) Determine viral loads in virus positive individuals to release them from quarantine (iii) Be deployed in hotspots to limit death and (iv) Quantify inflammatory biomarkers in individuals. However, like all weapons, we have to use diagnostics correctly and for the common good. As an example, if precise, but expensive diagnostics are developed, resource rich communities would benefit in the short term in contrast to resource poor communities. However, the virus knows no boundaries and therefore, a more powerful strain can subsequently attack all communities and cause long lasting damage. No diagnostic can satisfy all the requirements of all stakeholders and therefore, 
interpretation, using terms such as positive predictive value, negative predictive value, etc. instead of a simple yes/no result becomes more important. This perspective, hopefully, provides a clear picture of the different questions, nuances and challenges of this important weapon. A focus on the needs of the stakeholders; a collaborative approach towards diagnostics for all; clear and compelling messages for the general public; a lower emphasis on self-promotion; objective analysis of "novel" diagnostics and a deeper sense of humility knowing that this virus and its cousins do not readily allow us to "see" them, will help us develop quality ASSURED-SQVM diagnostics to mitigate the effects of this devastating pathogen.

Acknowledgements: We thank NIAID (1R61Al140475-01A1) for their generous support for research on point of care diagnostics. We also thank several colleagues whose insightful comments have improved this manuscript significantly.

\section{References:}

1. World Health Organization. Coronavirus Disease. 2020; Available from: https://covid19.who.int/.

2. Li, H., et al., Coronavirus disease 2019 (COVID-19): current status and future perspectives. Int J Antimicrob Agents, 2020: p. 105951.

3. Chen, N., et al., Epidemiological and clinical characteristics of 99 cases of 2019 novel coronavirus pneumonia in Wuhan, China: a descriptive study. Lancet, 2020. 395(10223): p. 507-513.

4. Goh, K.J., et al., Rapid Progression to Acute Respiratory Distress Syndrome: Review of Current Understanding of Critical IIIness from COVID-19 Infection. Ann Acad Med Singapore, 2020. 49(3): p. 108-118.

5. Thanh Le, T., et al., The COVID-19 vaccine development landscape. Nat Rev Drug Discov, 2020. 19(5): p. 305-306.

6. Binnicker, M.J., Emergence of a Novel Coronavirus Disease (COVID-19) and the Importance of Diagnostic Testing: Why Partnership between Clinical Laboratories, Public Health Agencies, and Industry Is Essential to Control the Outbreak. Clin Chem, 2020. 66(5): p. 664-666.

7. U.S. Bureau of Labor Statistics. Labor Force Statistics from the Current Population Survey. 2020; Available from: https://data.bls.gov/timeseries/LNS11000000.

8. Blustein, D.L., et al., Unemployment in the time of COVID-19: A research agenda. J Vocat Behav, 2020: p. 103436.

9. Altmann, D.M., D.C. Douek, and R.J. Boyton, What policy makers need to know about COVID-19 protective immunity. Lancet, 2020. 395(10236): p. 1527-1529.

10. Binnicker, M., Emergence of a novel coronavirus disease (covid-19) and the importance of diagnostic testing: Why partnership between clinical laboratories, public health agencies, and industry is essential to control the outbreak. Clinical Chemistry, 2020. 66(5): p. 664-666.

11. Salathé, M., et al., COVID-19 epidemic in Switzerland: on the importance of testing, contact tracing and isolation. Swiss Med Wkly, 2020. 150(11-12): p. w20225-.

12. Crystal Watson, A.C., James Blumenstock, Micheal Fraser, A National Plan to Enable Comprehensive COVID-19 Case Finding and Contact Tracing in the US. 2020, Johns Hopikins Bloomberg School of Public Health.

13. Hellewell, J., et al., Feasibility of controlling COVID-19 outbreaks by isolation of cases and contacts. Lancet Glob Health, 2020. 8(4): p. e488-e496.

14. Ranney, M.L., V. Griffeth, and A.K. Jha, Critical Supply Shortages - The Need for Ventilators and Personal Protective Equipment during the Covid-19 Pandemic. 2020. 382(18): p. e41.

15. Farrell, T.W., et al., AGS Position Statement: Resource Allocation Strategies and Age-Related Considerations in the COVID-19 Era and Beyond. J Am Geriatr Soc, 2020.

16. Singhal, T., A Review of Coronavirus Disease-2019 (COVID-19). Indian J Pediatr, 2020. 87(4): p. 281-286. 
17. Koh, D., Occupational risks for COVID-19 infection. Occup Med (Lond), 2020. 70(1): p. 3-5.

18. Tapper, E.B. and S.K. Asrani, The COVID-19 pandemic will have a long-lasting impact on the quality of cirrhosis care. J Hepatol, 2020.

19. Phua, J., et al., Intensive care management of coronavirus disease 2019 (COVID-19): challenges and recommendations. Lancet Respir Med, 2020. 8(5): p. 506-517.

20. Meng, L., et al., Intubation and Ventilation amid the COVID-19 Outbreak: Wuhan's Experience. Anesthesiology, 2020. 132(6): p. 1317-1332.

21. Belingheri, M., M.E. Paladino, and M.A. Riva, Beyond the assistance: additional exposure situations to COVID-19 for healthcare workers. J Hosp Infect, 2020.

22. Lan, J., et al., Structure of the SARS-CoV-2 spike receptor-binding domain bound to the ACE2 receptor. Nature, 2020. 581(7807): p. 215-220.

23. Rothan, H.A. and S.N. Byrareddy, The epidemiology and pathogenesis of coronavirus disease (COVID-19) outbreak. J Autoimmun, 2020. 109: p. 102433.

24. Moccia, F., et al., COVID-19-associated cardiovascular morbidity in older adults: a position paper from the Italian Society of Cardiovascular Researches. Geroscience, 2020.

25. Dietz, W. and C. Santos-Burgoa, Obesity and its Implications for COVID-19 Mortality. Obesity (Silver Spring), 2020. 28(6): p. 1005.

26. Lai, C.C., et al., Severe acute respiratory syndrome coronavirus 2 (SARS-CoV-2) and coronavirus disease-2019 (COVID-19): The epidemic and the challenges. Int J Antimicrob Agents, 2020. 55(3): p. 105924.

27. Jin, Y., et al., Virology, Epidemiology, Pathogenesis, and Control of COVID-19. Viruses, 2020. 12(4).

28. Vashist, S.K., In Vitro Diagnostic Assays for COVID-19: Recent Advances and Emerging Trends. Diagnostics (Basel), 2020. 10(4).

29. Xiang, F., et al., Antibody Detection and Dynamic Characteristics in Patients with COVID-19. Clin Infect Dis, 2020.

30. Adalja, A.A., E. Toner, and T.V. Inglesby, Priorities for the US Health Community Responding to COVID-19. JAMA, 2020.

31. Belingheri, M., M.E. Paladino, and M.A. Riva, COVID-19: Health prevention and control in nonhealthcare settings. Occup Med (Lond), 2020. 70(2): p. 82-83.

32. Dietz, L., et al., 2019 Novel Coronavirus (COVID-19) Pandemic: Built Environment Considerations To Reduce Transmission. mSystems, 2020. 5(2).

33. Mosites, E., et al., Assessment of SARS-CoV-2 Infection Prevalence in Homeless Shelters - Four U.S. Cities, March 27-April 15, 2020. MMWR Morb Mortal Wkly Rep, 2020. 69(17): p. 521-522.

34. Udugama, B., et al., Diagnosing COVID-19: The Disease and Tools for Detection. ACS Nano, 2020. 14(4): p. 3822-3835.

35. Datta, S., et al., Comparison of sputum collection methods for tuberculosis diagnosis: a systematic review and pairwise and network meta-analysis. Lancet Glob Health, 2017. 5(8): p. e760-e771.

36. Iyer, M., et al., COVID-19: an update on diagnostic and therapeutic approaches. BMB Rep, 2020. 53(4): p. 191-205.

37. Li, B., et al., Diagnostic value and key features of computed tomography in Coronavirus Disease 2019. Emerg Microbes Infect, 2020. 9(1): p. 787-793.

38. Jacofsky, D., E.M. Jacofsky, and M. Jacofsky, Understanding Antibody Testing for COVID-19. J Arthroplasty, 2020.

39. Jaaskelainen, A.J., et al., Evaluation of commercial and automated SARS-CoV-2 IgG and IgA ELISAs using coronavirus disease (COVID-19) patient samples. Euro Surveill, 2020. 25(18).

40. Rojas, M., et al., Convalescent plasma in Covid-19: Possible mechanisms of action. Autoimmun Rev, 2020: p. 102554.

41. Mehta, P., et al., COVID-19: consider cytokine storm syndromes and immunosuppression. Lancet, 2020. 395(10229): p. 1033-1034. 
42. Wang, W., et al., Detection of SARS-CoV-2 in Different Types of Clinical Specimens. JAMA, 2020.

43. van Kasteren, P.B., et al., Comparison of seven commercial RT-PCR diagnostic kits for COVID19. J Clin Virol, 2020. 128: p. 104412.

44. Yan, C., et al., Rapid and visual detection of 2019 novel coronavirus (SARS-CoV-2) by a reverse transcription loop-mediated isothermal amplification assay. Clin Microbiol Infect, 2020.

45. Baek, Y.H., et al., Development of a reverse transcription-loop-mediated isothermal amplification as a rapid early-detection method for novel SARS-CoV-2. Emerg Microbes Infect, 2020. 9(1): p. 998-1007.

46. Yang, T., et al., Point-of-Care RNA-Based Diagnostic Device for COVID-19. Diagnostics (Basel), 2020. 10(3).

47. Fischer, S.K., et al., Development of an IL-6 point-of-care assay: utility for real-time monitoring and management of cytokine release syndrome and sepsis. Bioanalysis, 2019. 11(19): p. 17771785.

48. Min, J., et al., Integrated Biosensor for Rapid and Point-of-Care Sepsis Diagnosis. ACS Nano, 2018. 12(4): p. 3378-3384.

49. Leland, D.S. and C.C. Ginocchio, Role of cell culture for virus detection in the age of technology. Clin Microbiol Rev, 2007. 20(1): p. 49-78.

50. Jackson, J.B., et al., Rapid and sensitive viral culture method for human immunodeficiency virus type 1. 1988. 26(7): p. 1416-1418.

51. Falsey, A.R., et al., Comparison of quantitative reverse transcription-PCR to viral culture for assessment of respiratory syncytial virus shedding. 2003. 41(9): p. 4160-4165.

52. Smith, C.J. and A.M. Osborn, Advantages and limitations of quantitative PCR (Q-PCR)-based approaches in microbial ecology. FEMS Microbiol Ecol, 2009. 67(1): p. 6-20.

53. Mitchell, S.L. and K.S. George, Evaluation of the COVID19 ID NOW EUA Assay. J Clin Virol, 2020: p. 104429.

54. Diel, R. and A. Nienhaus, Cost-Benefit Analysis of Real-Time Influenza Testing for Patients in German Emergency Rooms. Int J Environ Res Public Health, 2019. 16(13).

55. Tang, Y.W., et al., The Laboratory Diagnosis of COVID-19 Infection: Current Issues and Challenges. J Clin Microbiol, 2020.

56. Koczula, K.M. and A. Gallotta, Lateral flow assays. Essays Biochem, 2016. 60(1): p. 111-20.

57. Chen, Z., et al., Rapid and Sensitive Detection of anti-SARS-CoV-2 IgG, Using Lanthanide-Doped Nanoparticles-Based Lateral Flow Immunoassay. Anal Chem, 2020. 92(10): p. 7226-7231.

58. West, C.P., V.M. Montori, and P. Sampathkumar, COVID-19 Testing: The Threat of FalseNegative Results. Mayo Clin Proc, 2020.

59. Cheng, M.P., et al., Diagnostic Testing for Severe Acute Respiratory Syndrome-Related Coronavirus-2: A Narrative Review. Ann Intern Med, 2020.

60. Arnaldez, F.I., et al., The Society for Immunotherapy of Cancer perspective on regulation of interleukin-6 signaling in COVID-19-related systemic inflammatory response. J Immunother Cancer, 2020. 8(1).

61. Gnoth, C. and S. Johnson, Strips of Hope: Accuracy of Home Pregnancy Tests and New Developments. Geburtshilfe Frauenheilkd, 2014. 74(7): p. 661-669.

62. Schuchat, A. and C.C.-R. Team, Public Health Response to the Initiation and Spread of Pandemic COVID-19 in the United States, February 24-April 21, 2020. MMWR Morb Mortal Wkly Rep, 2020. 69(18): p. 551-556.

63. Kosack, C.S., A.L. Page, and P.R. Klatser, A guide to aid the selection of diagnostic tests. Bull World Health Organ, 2017. 95(9): p. 639-645.

64. Tidy, E.J., et al., Home self-testing kits: helpful or harmful? Br J Gen Pract, 2018. 68(673): p. 360361.

65. Hollander, J.E. and B.G. Carr, Virtually Perfect? Telemedicine for Covid-19. N Engl J Med, 2020. 382(18): p. 1679-1681. 
66. Alteri, C., et al., Quantification of HIV-DNA and residual viremia in patients starting ART by droplet digital PCR: Their dynamic decay and correlations with immunological parameters and virological success. J Clin Virol, 2019. 117: p. 61-67.

67. Li, X., et al., Molecular immune pathogenesis and diagnosis of COVID-19. J Pharm Anal, 2020. 10(2): p. 102-108.

68. Graham, H., D.J. Chandler, and S.A. Dunbar, The genesis and evolution of bead-based multiplexing. Methods, 2019. 158: p. 2-11.

69. Faust, J.S. and C. Del Rio, Assessment of Deaths From COVID-19 and From Seasonal Influenza. JAMA Intern Med, 2020.

70. Shirey, K.A., et al., Influenza "Trains" the Host for Enhanced Susceptibility to Secondary Bacterial Infection. mBio, 2019. 10(3).

71. Mameli, C., et al., Influenza Vaccination: Effectiveness, Indications, and Limits in the Pediatric Population. Front Pediatr, 2019. 7: p. 317.

72. Grohskopf, L.A., et al., Prevention and Control of Seasonal Influenza with Vaccines: Recommendations of the Advisory Committee on Immunization Practices - United States, 201920 Influenza Season. MMWR Recomm Rep, 2019. 68(3): p. 1-21.

73. Riphagen, S., et al., Hyperinflammatory shock in children during COVID-19 pandemic. Lancet, 2020.

74. Mahase, E., Covid-19: concerns grow over inflammatory syndrome emerging in children. BMJ, 2020. 369: p. $\mathrm{m} 1710$. 
Figures:

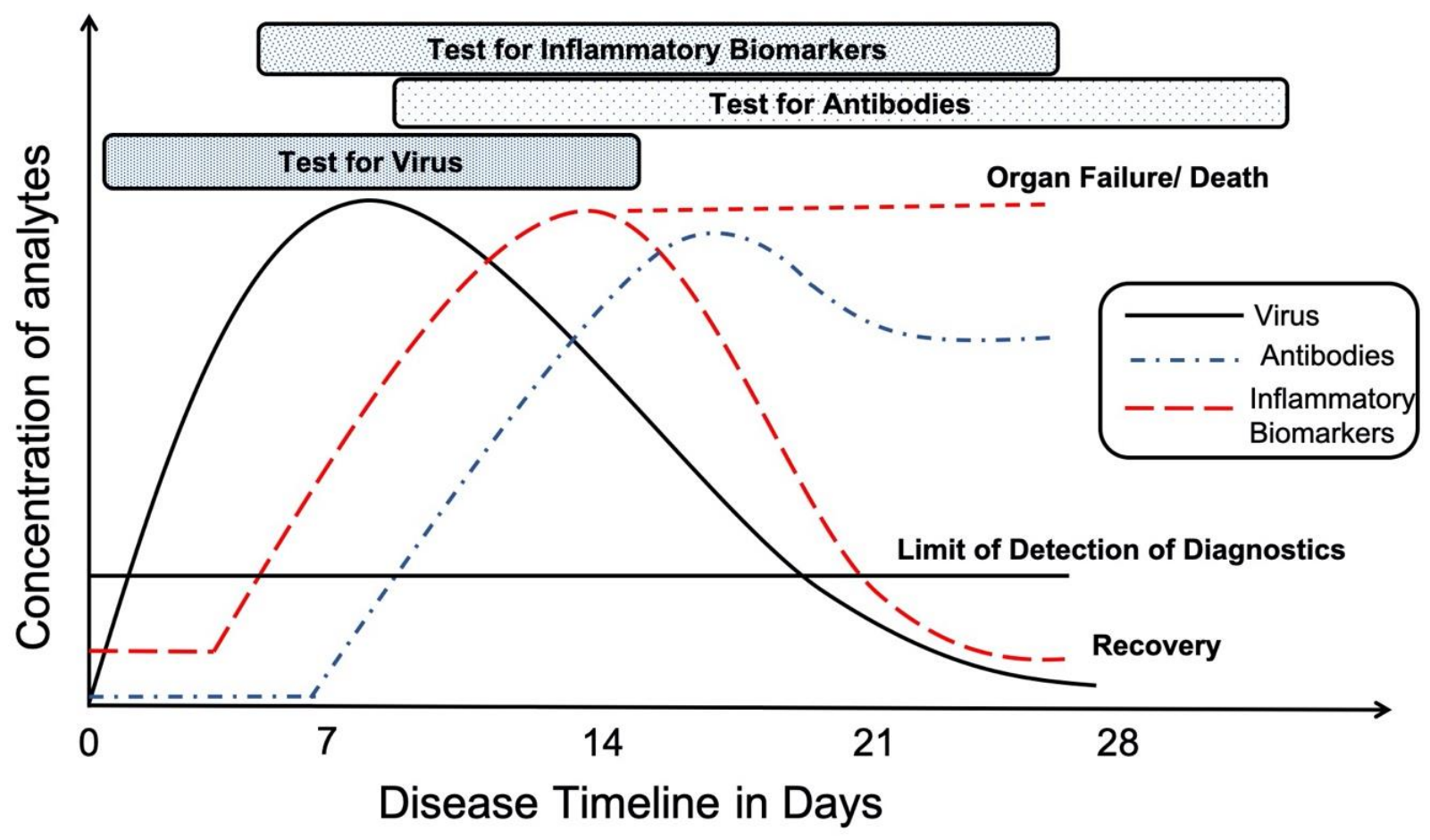

Figure 1. Timeline and concentration of analytes for diagnostic assays after onset of SARS-CoV-2 infection at day zero. 


\section{A. RT-PCR}

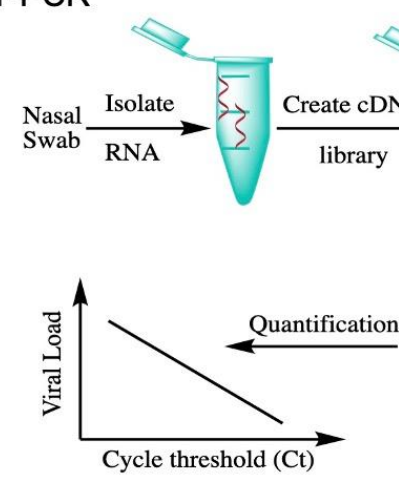

C. Plaque Assay

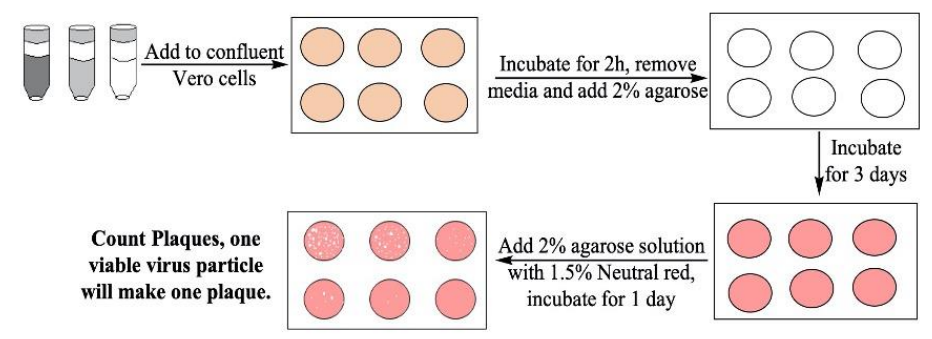

B. ELISA

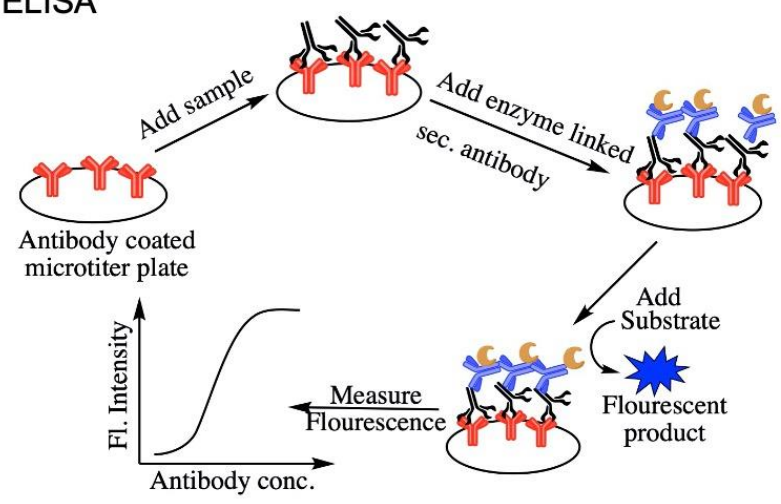

D. Lateral Flow Assay

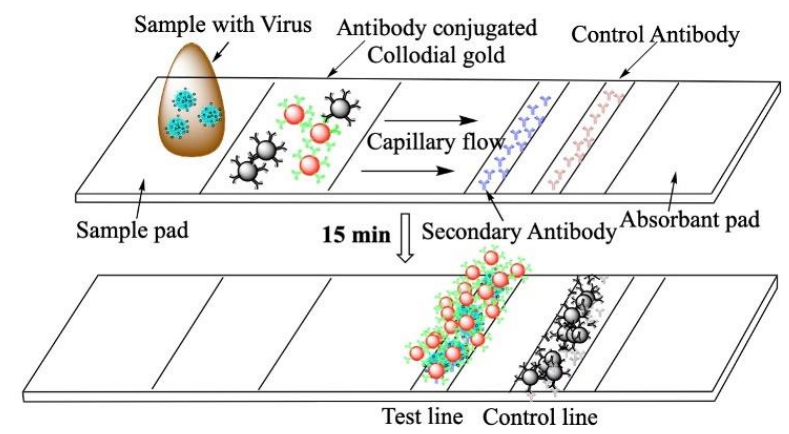

Figure 2. Schematic of some of the tests used to detect SARS-CoV-2. 


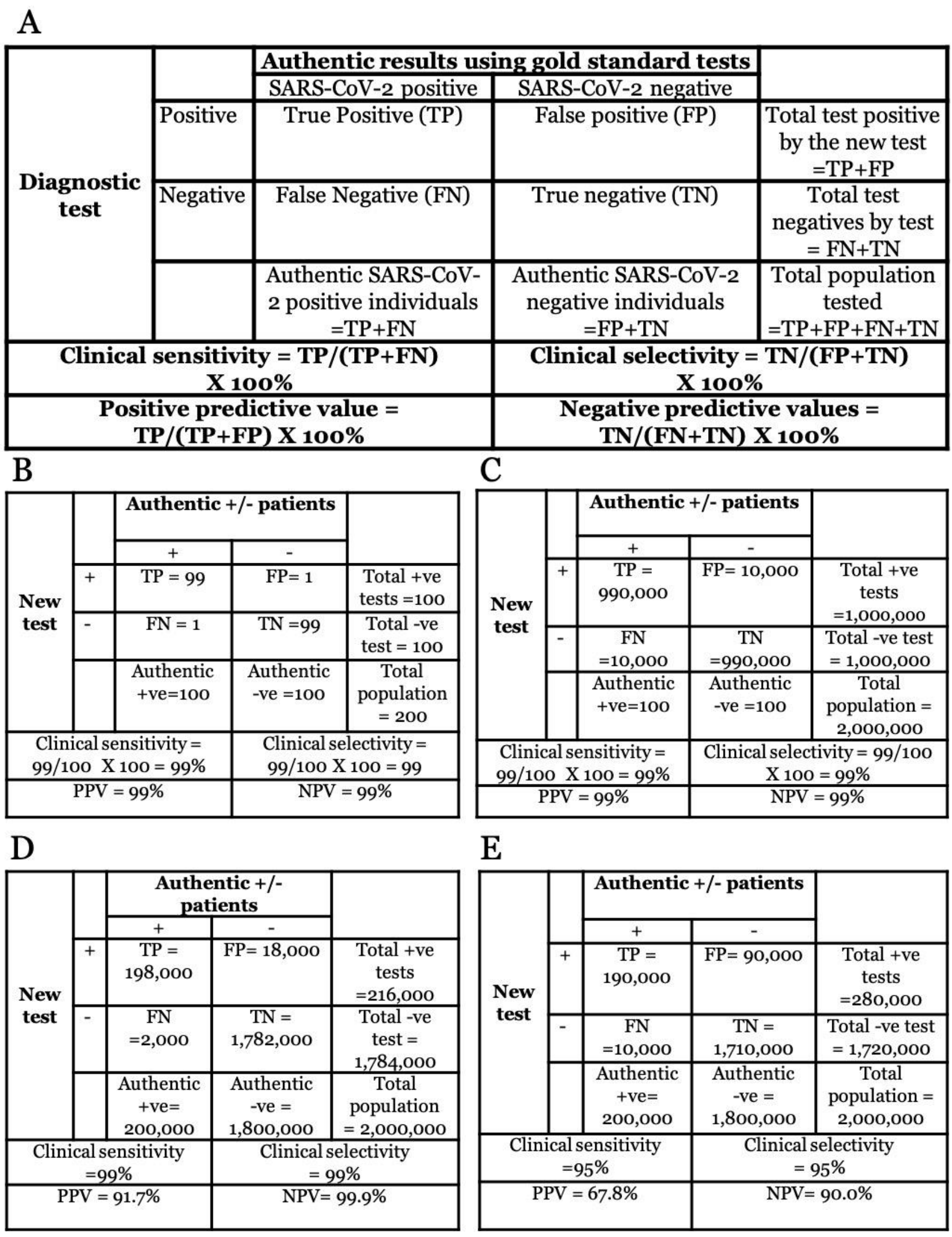


Figure 3. (A) Some of the terms and their derivations used in clinical diagnostics. (B) Situation 1: If 200 tests with excellent clinical selectivity and sensitivity of $99 \%$ and $50 \%$ disease prevalence are performed, only 2 individuals will be misdiagnosed as false positive or false negative. (C) Situation 2: If 2 million tests with similar parameters as in situation 1 are performed, 20,000 individuals will be misdiagnosed as false positives or false negatives. (D) Situation 3: If the disease prevalence decreases to a more realistic situation observed in the current COVID-19 pandemic, 2,000 individuals will receive a false negative result and 18,000 individuals will receive a false positive result. (E) Situation 4: If the test has $95 \%$ clinical selectivity and sensitivity with 10\% disease prevalence, 10,000 individuals will receive a false negative result and 90,000 individuals will receive a false positive result. The last situation is more indicative of most diagnostics in the current COVID-19 pandemic even if a manufacturer claims $99 \%$ clinical selectivity and sensitivity, because human errors (eg. Incorrect sample collection, variability in nasal/throat swabs, etc.) increase when tests are performed in the field. 
4A.

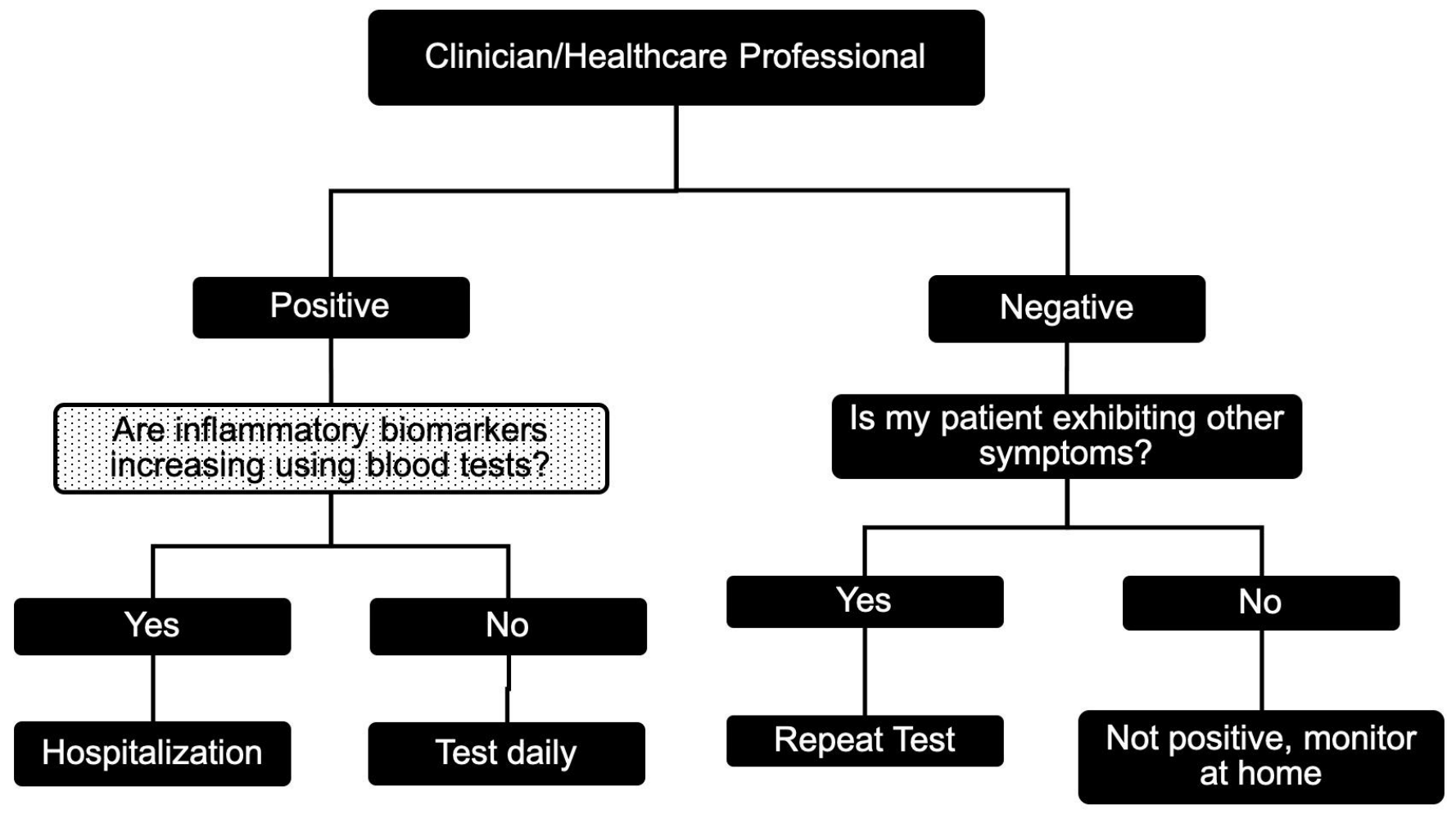

4B.

\section{Policy Makers/ Government Officials}

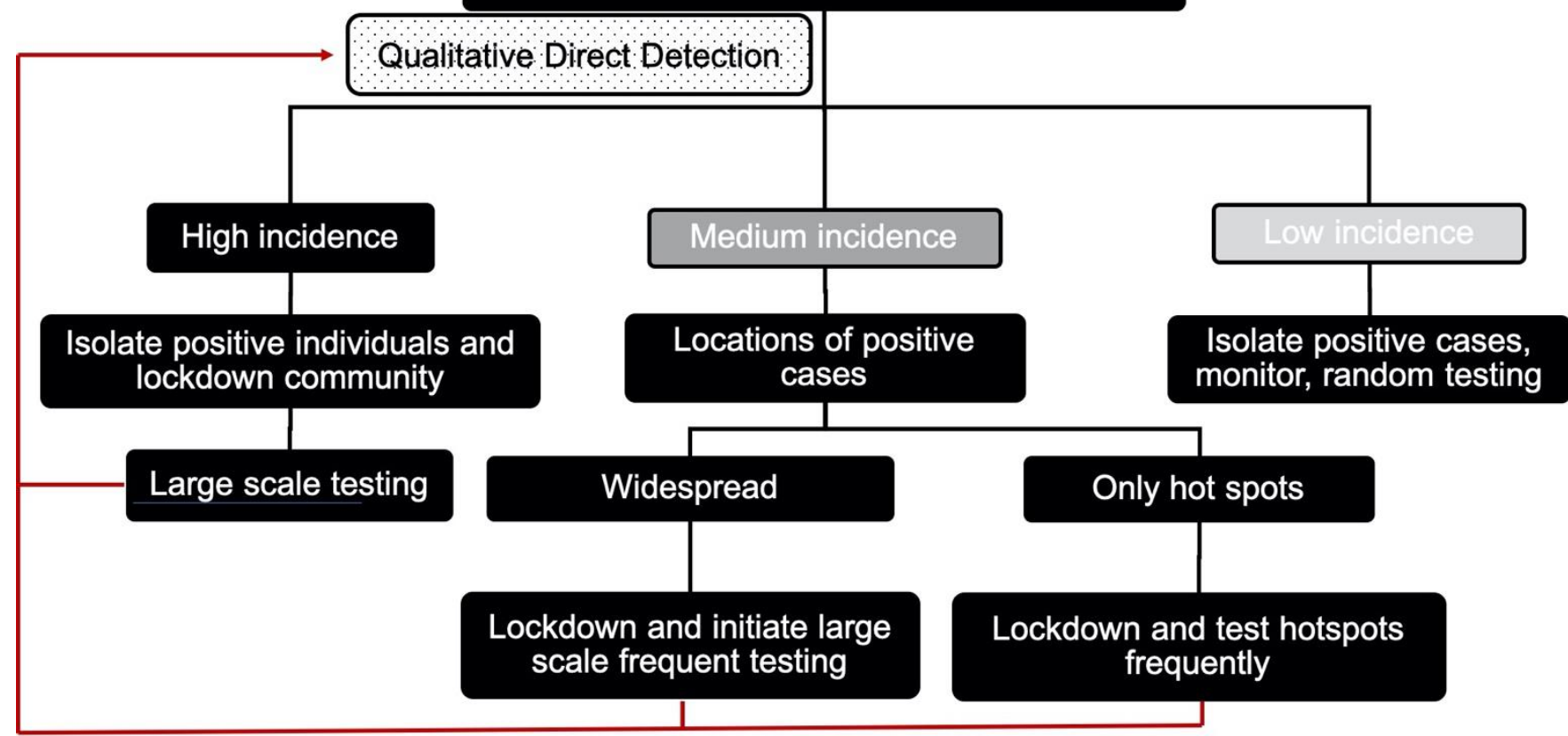


4C.

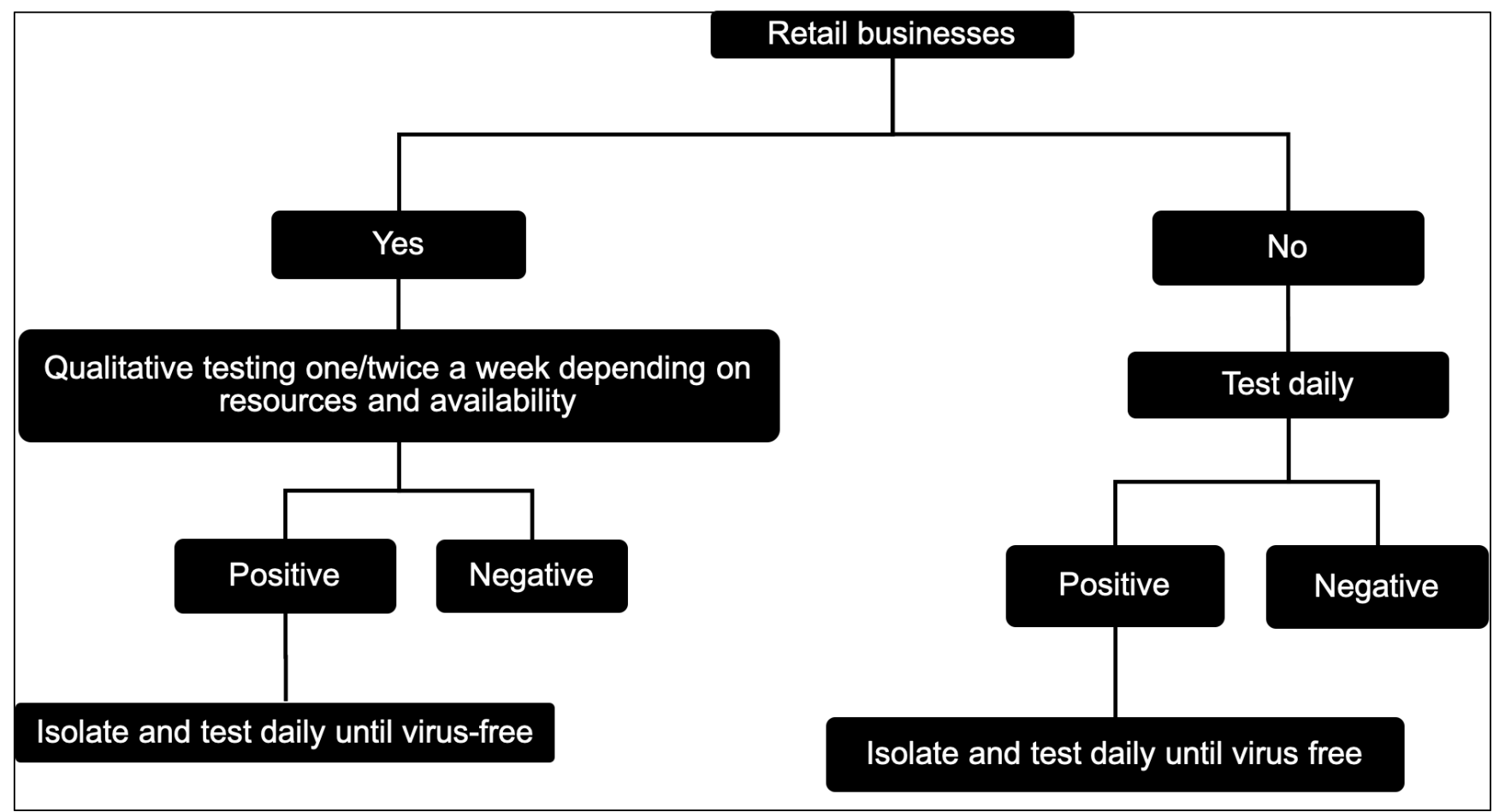

4D.

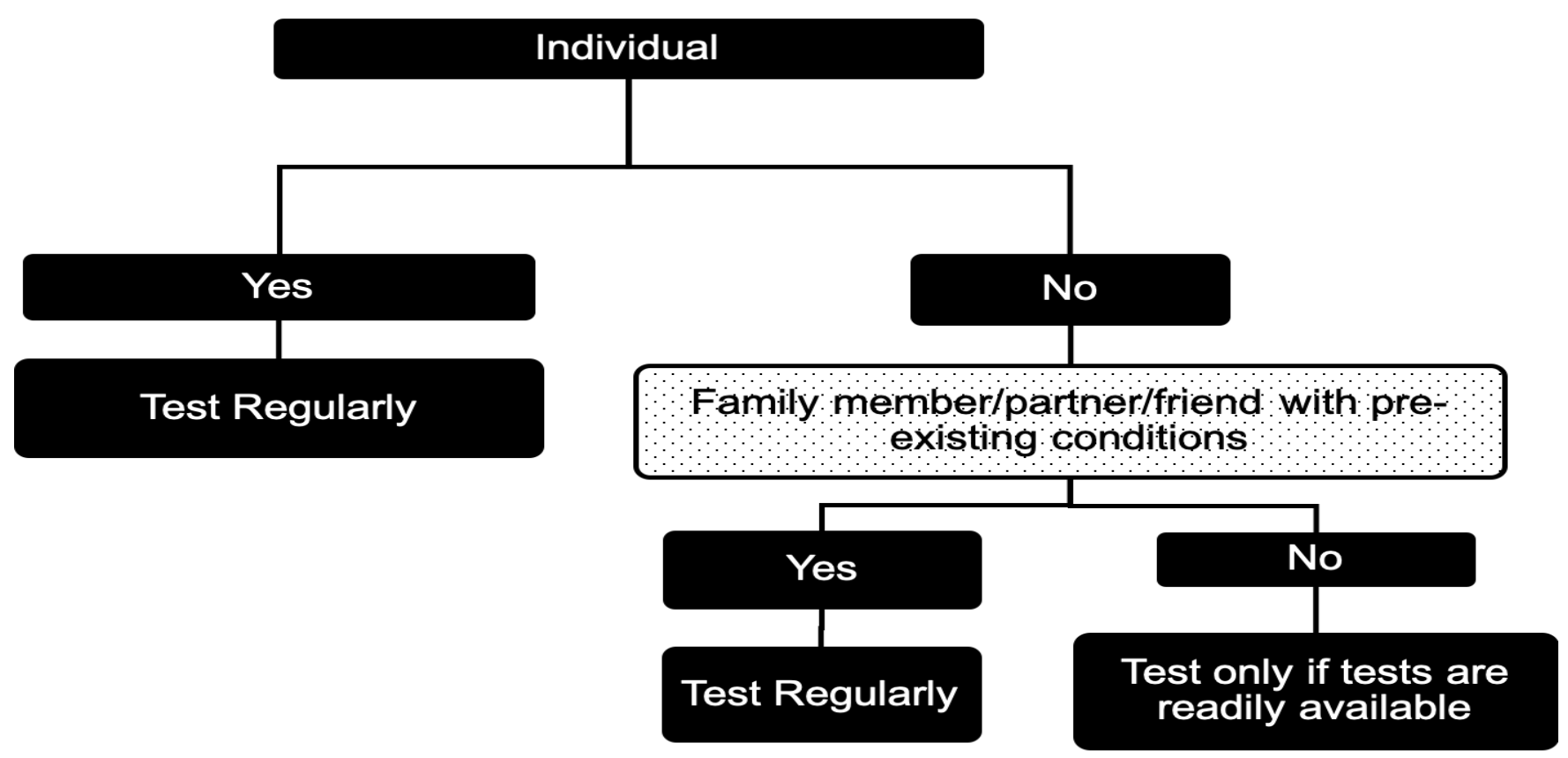

Figure 4. Examples of decision trees based on excellent diagnostics for stakeholders. A. Clinician/Healthcare professional. B. Policymakers. C. Retail business. D. Individual. These decision trees are not exhaustive and doesn't take other factors specific to a particular situation into consideration. 


\begin{tabular}{|c|c|c|c|c|c|}
\hline \multirow{3}{*}{ Criteria } & \multicolumn{5}{|c|}{ Detection methods } \\
\hline & \multicolumn{3}{|c|}{ Direct detection of virus } & \multirow{2}{*}{$\begin{array}{l}\text { Detection of } \\
\text { antibodies }\end{array}$} & \multirow{2}{*}{$\begin{array}{l}\text { Detection of } \\
\text { inflammatory } \\
\text { biomarkers }\end{array}$} \\
\hline & Culture & Nucleic Acid & $\begin{array}{l}\text { Antigen } \\
\text { capture }\end{array}$ & & \\
\hline Affordable & $\begin{array}{l}\text { No, requires } \\
\text { laboratory } \\
\text { setting, } \\
\text { trained } \\
\text { personnel }\end{array}$ & $\begin{array}{l}\text { No. Instrument, } \\
\text { consumables } \\
\text { are expensive }\end{array}$ & Yes & Yes & $\begin{array}{l}\text { Requires a clinical } \\
\text { laboratory to perform the } \\
\text { tests for multiple } \\
\text { biomarkers }\end{array}$ \\
\hline Sensitive & Very high & High & $\begin{array}{l}\text { Depends on the } \\
\text { QC of the } \\
\text { antibodies and } \\
\text { manufacturer }\end{array}$ & $\begin{array}{l}\text { Depends on the } \\
\text { QC of the } \\
\text { antibodies and } \\
\text { manufacturer }\end{array}$ & $\begin{array}{c}\text { Depends on the QC of } \\
\text { the antibodies and } \\
\text { manufacturer }\end{array}$ \\
\hline Selective & Very high & $\begin{array}{l}\text { Very high, but } \\
\text { requires the } \\
\text { right primers }\end{array}$ & $\begin{array}{l}\text { Depends on the } \\
\text { QC of the } \\
\text { antibodies and } \\
\text { manufacturer }\end{array}$ & $\begin{array}{l}\text { Depends on the } \\
\text { QC of the } \\
\text { antibodies and } \\
\text { manufacturer }\end{array}$ & $\begin{array}{c}\text { Depends on the QC of } \\
\text { the antibodies and } \\
\text { manufacturer }\end{array}$ \\
\hline Rapid & $\begin{array}{c}\text { No, requires } \\
\text { days. }\end{array}$ & $\begin{array}{l}\text { Tabletop } \\
\text { instruments } \\
\text { provide results } \\
\text { in } \leq 15 \text { min }\end{array}$ & $\begin{array}{l}\text { Lateral flow } \\
\text { tests will provide } \\
\text { results in } \leq 15 \\
\text { min. }\end{array}$ & $\begin{array}{l}\text { Lateral flow tests } \\
\text { will provide } \\
\text { results in } \leq 15 \\
\text { min. }\end{array}$ & $\begin{array}{c}\text { Blood tests take } 24-28 \\
\text { hours }\end{array}$ \\
\hline Robust & $\begin{array}{l}\text { No, reagents } \\
\text { require } \\
\text { refrigeration. }\end{array}$ & $\begin{array}{l}\text { Yes/No, some } \\
\text { reagents may } \\
\text { require } \\
\text { refrigeration }\end{array}$ & $\begin{array}{l}\text { No, depends on } \\
\text { antibody } \\
\text { stability. May } \\
\text { require } \\
\text { refrigeration }\end{array}$ & $\begin{array}{l}\text { No, depends on } \\
\text { antibody stability. } \\
\text { May require } \\
\text { refrigeration }\end{array}$ & $\begin{array}{l}\text { No, reagents require } \\
\text { refrigeration }\end{array}$ \\
\hline User-friendly & $\begin{array}{l}\text { No, requires } \\
\text { trained } \\
\text { personnel }\end{array}$ & $\begin{array}{l}\text { Only the new } \\
\text { integrated } \\
\text { systems are } \\
\text { user friendly. }\end{array}$ & Yes & Yes & $\begin{array}{l}\text { No, requires trained } \\
\text { personnel }\end{array}$ \\
\hline $\begin{array}{l}\text { Equipment } \\
\text { free }\end{array}$ & No & No & Yes & Yes & No \\
\hline $\begin{array}{l}\text { Deliverable to } \\
\text { end users }\end{array}$ & $\begin{array}{l}\text { No, requires } \\
\text { laboratory }\end{array}$ & $\begin{array}{l}\text { No, requires } \\
\text { space, } \\
\text { electricity }\end{array}$ & $\begin{array}{l}\text { Yes, small } \\
\text { footprint, } \\
\text { portable }\end{array}$ & $\begin{array}{c}\text { Yes, small } \\
\text { footprint, portable }\end{array}$ & No, requires laboratory \\
\hline Self-testing & No & No & Yes & Yes & No \\
\hline Quantitative & $\begin{array}{l}\text { Yes, but } \\
\text { takes days }\end{array}$ & $\begin{array}{c}\text { Tabletop } \\
\text { systems provide } \\
\text { yes/no answer; }\end{array}$ & No & No & $\begin{array}{c}\text { Yes, but takes } \\
\text { hours/days }\end{array}$ \\
\hline Viability & Yes & No & No & $\mathrm{N} / \mathrm{A}$ & $\mathrm{N} / \mathrm{A}$ \\
\hline Multiplexing & $\begin{array}{l}\text { Yes, but } \\
\text { requires } \\
\text { equipment }\end{array}$ & $\begin{array}{l}\text { Capability } \\
\text { exists, but is } \\
\text { expensive }\end{array}$ & $\begin{array}{c}\text { Yes, but } \\
\text { becomes more } \\
\text { expensive }\end{array}$ & $\begin{array}{c}\text { Yes, but } \\
\text { becomes more } \\
\text { expensive }\end{array}$ & $\begin{array}{l}\text { Yes, but requires } \\
\text { equipment }\end{array}$ \\
\hline
\end{tabular}

Table 1: ASSURED-SQVM principles as applied to current diagnostics for SARS-CoV-2 and other infectious diseases 


\begin{tabular}{|c|c|}
\hline Term & Definition and explanation \\
\hline $\begin{array}{l}\text { Limit of detection (LOD) } \\
\text { or Analytical Sensitivity }\end{array}$ & $\begin{array}{l}\text { LOD is defined as the lowest concentration of virus that can be detected using the } \\
\text { diagnostic. The LOD is typically given by the manufacturer of the test and that may } \\
\text { vary according to the test characteristics. For example, a nucleic acid based test } \\
\text { may be able to detect } 10 \text { viral particles, whereas the LOD of an antigen test may } \\
\text { be } 100 \text { particles. Manufacturers also use LOQ, or the limit of quantification, which } \\
\text { is the lowest concentration detected with a high degree of accuracy. LOD is also } \\
\text { referred to as Analytical Sensitivity, which is the lowest number of viral particles } \\
\text { the test can detect. Researchers generate a series of vials with different } \\
\text { concentrations of the virus and test is a positive result is obtained with the different } \\
\text { vials. The vial with the lowest concentration is considered the LOD. }\end{array}$ \\
\hline Analytical Selectivity & $\begin{array}{l}\text { Analytical selectivity is the ability of the test to only detect SARS-CoV-2 in the } \\
\text { presence of other pathogens, including closely related strains such as SARS- } \\
\text { CoV-2, MERS and other respiratory pathogens such as rhinovirus, influenza, } \\
\text { Streptococcus pneumonia, etc. Different concentrations of these pathogens are } \\
\text { used to determine if the test yields a positive result. Next, low concentrations of } \\
\text { SARS-CoV-2 are mixed with high concentrations of one or more pathogens to } \\
\text { determine the specificity. }\end{array}$ \\
\hline $\begin{array}{l}\text { Clinical or diagnostic } \\
\text { sensitivity }\end{array}$ & $\begin{array}{l}\text { Clinical or diagnostic sensitivity is very different from analytical sensitivity. The } \\
\text { latter is associated with the test specifications, the former is the ability of the test } \\
\text { to accurately determine SARS-CoV-2 positive patients. Clinical sensitivity has to } \\
\text { be benchmarked against gold standard diagnostics. }\end{array}$ \\
\hline $\begin{array}{l}\text { Clinical or diagnostic } \\
\text { selectivity }\end{array}$ & $\begin{array}{l}\text { It is the ability of the test to accurately determine SARS-CoV-2 negative patients. } \\
\text { Clinical selectivity has to be benchmarked against gold standard diagnostics. }\end{array}$ \\
\hline $\begin{array}{l}\text { Positive predictive } \\
\text { value }\end{array}$ & $\begin{array}{l}\text { Positive predictive value is the probability that an individual will definitely have } \\
\text { the disease based on a positive result. }\end{array}$ \\
\hline $\begin{array}{l}\text { Negative predictive } \\
\text { value }\end{array}$ & $\begin{array}{l}\text { Negative predictive value is the probability that an individual may not have the } \\
\text { virus based on a negative result }\end{array}$ \\
\hline True positive & $\begin{array}{l}\text { When a test result is positive, and the individual has SARS-CoV-2 based on } \\
\text { additional advanced confirmatory validated tests such as cell culture and or } \\
\text { central laboratory based RT-PCR. }\end{array}$ \\
\hline False positive & $\begin{array}{l}\text { When a test result is positive, but the individual does not have SARS-CoV-2. The } \\
\text { implication is that the individual will have to be quarantined. Here, the individual } \\
\text { will suffer on a more personal level from the wrong result. }\end{array}$ \\
\hline True negative & $\begin{array}{l}\text { When a test result is negative and the individual does not have SARS-CoV-2 } \\
\text { based on additional advanced confirmatory validated tests such as cell culture } \\
\text { and or central laboratory based RT-PCR. }\end{array}$ \\
\hline False negative & $\begin{array}{l}\text { When a test result is negative, but the individual has SARS-CoV-2. The } \\
\text { implication is that the individual will spread the virus. Here, the community will } \\
\text { suffer as more people will be infected. }\end{array}$ \\
\hline
\end{tabular}

Table 2: Some of the common terms used in diagnostics. 